\title{
Thyroid function in children and adolescents with Hashimoto's thyroiditis after L-thyroxine discontinuation
}

\author{
Giorgio Radetti ${ }^{1}$, Mariacarolina Salerno$^{2}$, Chiara Guzzetti ${ }^{3}$, Marco Cappa ${ }^{4}$, \\ Andrea Corrias ${ }^{5}$, Alessandra Cassio ${ }^{6}$, Graziano Cesaretti7, Roberto Gastaldi ${ }^{8}$, \\ Mario Rotondi ${ }^{9}$, Fiorenzo Lupi ${ }^{1}$, Antonio Fanolla ${ }^{10}$, Giovanna Weber ${ }^{11}$ and \\ Sandro Loche ${ }^{3}$ \\ ${ }^{1}$ Pediatrics, Regional Hospital, Bolzano, Italy \\ ${ }^{2}$ Pediatrics, University Federico II, Naples, Italy \\ ${ }^{3}$ Pediatric Endocrinology, Ospedale Pedatrico Microcitemico 'A. Cao' - AOB Cagliari, Cagliari, Italy \\ ${ }^{4}$ Pediatric Endocrinology, Bambino Gesù Children Hospital, Roma, Italy \\ ${ }^{5}$ Divisione di Endocrinologia Pediatrica, Ospedale Infantile Regina Margherita, Torino, Italy \\ ${ }^{6}$ Department of Pediatrics, University of Bologna, Bologna, Italy \\ ${ }^{7}$ Department of Pediatrics, University of Pisa, Pisa, Italy \\ ${ }^{8}$ Paediatric Department, Gaslini Hospital, Genova, Italy \\ ${ }^{9}$ Unit of Internal Medicine and Endocrinology, Fondazione Salvatore Maugeri I.R.C.C.S. \\ ISPESL Laboratory for Endocrine Disruptors, University of Pavia, Pavia, Italy \\ ${ }^{10}$ Department of Biostatistics, Regional Hospital, Bolzano, Italy \\ ${ }^{11}$ Department of Pediatrics, Vita-Salute San Raffaele University, Milan, Italy
}

Correspondence

should be addressed

to G Radetti

Email

giorgio.radetti@gmail.com

\footnotetext{
Abstract

Objective: Thyroid function may recover in patients with Hashimoto's thyroiditis (HT). Design: To investigate thyroid function and the need to resume L-thyroxine treatment after its discontinuation.

Setting: Nine Italian pediatric endocrinology centers.

Patients: 148 children and adolescents ( $25 \mathrm{~m}$ and $123 \mathrm{f}$ ) with HT on treatment with L-thyroxine for at least one year.

Intervention and main outcome measure: Treatment was discontinued in all patients, and serum TSH and fT4 concentrations were measured at the time of treatment discontinuation and then after 2, 6, 12 and 24 months. Therapy with L-thyroxine was re-instituted when TSH rose $>10 \mathrm{U} / \mathrm{L}$ and/or fT4 was below the normal range. The patients were followed up when TSH concentrations were between 5 and $10 \mathrm{U} / \mathrm{L}$ and fT4 was in the normal range.

Results: At baseline, TSH was in the normal range in 139 patients, and was between 5 and $10 \mathrm{U} / \mathrm{L}$ in 9 patients. Treatment was re-instituted after 2 months in 37 (25.5\%) patients, after 6 months in 13 patients (6.99\%), after 12 months in 12 patients $(8.6 \%)$, and after 24 months in an additional 3 patients (3.1\%). At 24 months, 34 patients (34.3\%) still required no treatment. TSH concentration $>10 \mathrm{U} / \mathrm{L}$ at the time of diagnosis was the only predictive factor for the deterioration of thyroid function after L-thyroxine discontinuation. Conclusions: This study confirms that not all children with HT need life-long therapy with I-thyroxine, and the discontinuation of treatment in patients with a TSH level $<10 \mathrm{U} / \mathrm{L}$ at the time of diagnosis should be considered.
}
Key Words
- Hashimoto's thyroiditis
- children
- L-thyroxine treatment
- subclinical hypothyroidism
- autoimmune thyroiditis

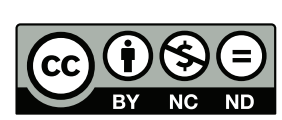

This work is licensed under a Creative Commons Attribution-NonCommercial-NoDerivatives 4.0 International License. 


\section{Introduction}

Hashimoto's thyroiditis (HT) is a frequent autoimmune disease that may present with a spectrum of altered thyroid function ranging from thyrotoxicosis to overt hypothyroidism. Treatment with L-thyroxine (L-T4) is commonly started in patients with either subclinical (high TSH with normal fT4) or overt hypothyroidism (subnormal fT4 and increased TSH). There is no consensus on the timing to start or discontinue therapy based on TSH concentrations in children and adolescents $(1,2,3)$, even if current recommendations indicate that treatment should be considered in patients with serum TSH $>10 \mathrm{U} / \mathrm{L}(4)$.

Rallison, in a 20-year follow-up study (5), showed that in a substantial number of patients thyroid function might remain unchanged or even normalize over the years. Recently, we could confirm these results in two follow-up studies $(6,7,8)$, in agreement with other authors $(9,10)$ also showing a relatively stable condition in HT children and adolescents. However, it is not well understood who are the patients needing life-long treatment and who can discontinue therapy. Even testing for thyroid function recovery by means of TRH stimulation during treatment did not reach a general acceptance (11).

We hypothesized that some children with HT on treatment with L-T4 may no longer need it. Thus, this study was designed to investigate how many HT patients treated with L-T4 maintain a normal thyroid function after therapy discontinuation. In addition, we looked for potential predictive markers to aid in the decision to treat or stop therapy. To test this hypothesis, we discontinued treatment in a large group of children with HT and followed them closely for two years.

\section{Subjects and methods}

\section{Subjects}

The study was performed between May 2011 and September 2013. The study group was comprised of 149 consecutive patients (26 males and 123 females) attending the outpatient clinics of nine Italian pediatric endocrinology centers. The patients were all born at full-term and not obese. The diagnosis of HT was made at a mean chronological age of $9.67 \pm 2.65$ years and was based on the presence of thyroid peroxidase antibody (TPOAb) and/or thyroglobulin antibody (TGAb), together with the typical ultrasound pattern. All the children had been treated with L-T4 for more than 1 year $(4.1 \pm 2.6$; range 1-12 years). Not all children started treatment at diagnosis, because they were still euthyroid, but only later, during the follow-up, based on the thyroid function tests. TSH concentrations at diagnosis ranged from 5.0 to $>1000$ U/L $(37.9 \pm 121.4)$. Free T4 was within the normal range in 84 patients (57\%), and below the normal range in $64(43 \%)$. Seven patients had celiac disease and 2 had vitiligo. No patients were affected with Turner or Down's syndrome. A positive family history for autoimmune diseases was present in $71(47.7 \%)$ of the patients. The study protocol followed the ethical principles outlined by the Helsinki Declaration. All protocols were approved by Partners Institutional Review Board. Written informed consent was obtained from all participants.

\section{Study design}

The children were admitted to the ward after an overnight fast for auxological evaluation. In all children, a blood sample was taken for measurement of serum fT4, TSH, thyroid peroxidase antibodies (TPOAb), thyroglobulin antibodies (TGAb), glucose, insulin, total and HDL cholesterol, and triglycerides. Chemokine CXCL10 was also measured in a subset of 35 subjects. Insulin sensitivity was evaluated with QUICKI $=1 /\left(\log \left(I_{0}\right)+\log \left(G_{0}\right)\right)$, where $I_{0}$ is the fasting insulin and $G_{0}$ is the fasting glucose (12). A thyroid ultrasound was performed in all subjects.

Therapy with L-T4 was discontinued within 2 weeks, halving the dose in the first and in the second week. TSH and fT4 were measured after 2, 6, 12 and 24 months. In the 64 subjects with subnormal fT4 and/or TSH concentrations $>100 \mathrm{U} / \mathrm{L}$ at diagnosis, thyroid function was checked after 1 month, and the parents were instructed how to verify the presence of signs/symptoms of hypothyroidism. Treatment with L-T4 was restarted when TSH rose $>10 \mathrm{U} / \mathrm{L}$ and/or fT4 decreased below the normal range. Monitoring and follow-up were continued in subjects with TSH concentrations between 5 and $10 \mathrm{U} / \mathrm{L}$ and a normal fT4. After 12 months, all auxological parameters were re-evaluated along with measurement of serum glucose, insulin, total and HDL cholesterol, triglycerides and QUICKI. Thyroid ultrasound was also repeated.

\section{Methods}

Anthropometric evaluation The children were admitted to the ward in the morning. All underwent an

This work is licensed under a Creative Commons Attribution-NonCommercial-NoDerivatives 4.0 International License. 
anthropometric assessment including height, weight and pubertal stage evaluation. Standing height was measured using a wall-mounted Harpenden stadiometer. Weight was obtained with a traditional balance scale to the nearest $0.1 \mathrm{~kg}$. Body mass index (BMI) was calculated as weight $(\mathrm{kg})$ divided by height squared $\left(\mathrm{m}^{2}\right)$. Height and BMI were then expressed as standard deviation score (SDS) according to the Italian standards (13). The patients were classified as prepubertal or pubertal according to the standard Tanner's criteria (G1, G2-G5 for males and B1, B2-B5 for females) (14).

Thyroid ultrasound Ultrasound was performed in each center by the same observer, who was well trained in thyroid imaging, using a $7.5 \mathrm{MHz}$ transducer. The volume of the thyroid gland was calculated using the formula for a prolate ellipse: Volume $=0.5 \times(\mathrm{L} \times \mathrm{D} \times \mathrm{W})$ where $\mathrm{L}$ is the length, $\mathrm{D}$ is the anterior-posterior depth and $\mathrm{W}$ is the transverse width of the gland. Typical ultrasound findings for a diagnosis of Hashimoto's thyroiditis are a hypoechogenic signal with a dyshomogeneous structure. The alterations of echogenicity and homogeneity of the parenchyma were further quantified according to a pediatric scoring system (15): score 0: normal, score 1: mild parceled hypoechogenicity, score 2: severe parceled hypoechogenicity, score 3: mild generalized hypoechogenicity, score 4: severe generalized hypoechogenicity, score 5: near-anechogenicity. We refer to this score system throughout the manuscript as thyroid score (TS).

Assays Serum glucose was measured with automatic analyzers, using a hexokinase enzymatic method. Serum insulin was measured with an immunoradiometric assay (Immulite 2000 Insulin, DPC, LA, CA), with an intra- and inter-assay CV of $8.3 \%$ and $8.6 \%$, respectively. Total and HDL cholesterol and triglycerides were measured enzymatically by an automatic photometric method (Olympus Diagnostica Gmbh, Lismeehan, O'Callaghan's Mills Co. Clare, Ireland). TSH was measured by a chemiluminescent immunometric assay (Roche Diagnostics); the intra- and inter-assay CV were $2.7 \%$ and $3.2 \%$, respectively, and the sensitivity limit was $0.005 \mathrm{U} / \mathrm{L}$. Measurement of fT4 was performed by chemiluminescent immunometric assay (Roche Diagnostics); the intra- and inter-assay CV were $1.8 \%$ and $2.6 \%$, respectively, and the sensitivity limit was $0.3 \mathrm{pmol} / \mathrm{L}$. Anti-thyroglobulin antibodies (TGAb) were measured by a chemiluminescent immunometric assay (Immulite 2000 Anti-TG Ab, DPC, LA, USA) with an

http://www.endocrineconnections.org DOI: 10.1530/EC-17-0023

(C) 2017 The authors Published by Bioscientifica Ltd intra- and inter-assay CV of 3.2\% and $4.6 \%$, respectively, with a sensitivity limit of $2.2 \mathrm{U} / \mathrm{mL}$. Anti-thyroid peroxidase antibodies (TPO-Ab) were measured by chemiluminescent immunometric assay (Immulite 2000 Anti-TG Ab, DPC, LA, USA) with an intra- and inter-assay $\mathrm{CV}$ of $5.2 \%$ and $3.2 \%$, respectively, and a sensitivity limit of $5 \mathrm{U} / \mathrm{mL}$. The concentrations of CXCL10 in the patients' serum were measured using commercially available kits (R\&D Systems). The mean minimum detectable dose of CXCL10 was $1.67 \mathrm{pg} / \mathrm{mL}$. The intra- and inter-assay coefficients of variation were $3.0 \%$ and $6.1 \%$, respectively. Samples were assayed in duplicate. Quality control pools for low, normal or high concentrations were included in each assay.

\section{Statistical analysis}

Data are shown as mean \pm s.D. Differences between baseline and 12 months in the auxological and laboratory data were evaluated by the paired $t$-test. Two-way mixed ANOVA analysis was used to evaluate the effects of the between- and within-subjects variable and the two-way interactions. Variable for the within-subjects analysis was the time when TSH was measured (diagnosis, stop treatment, and 2 months after discontinuing the treatment). Variables considered for the between-subjects analysis were auxological data, goiter volume, degree of hypoechogenity, TPOAb, TGAb, fT4 and CXCL10. Simple effects comparisons for the interaction were evaluated with the differences of least-squares means (TukeyKramer adjustment).

Logistic regression with ROC curve was used to assess whether TSH serum level at diagnosis could predict a TSH level $>10 \mathrm{U} / \mathrm{L}, 2$ months after stopping therapy. A $P$ value of less than 0.05 indicates statistical significance. The StatView statistical software 4.3 (SAS Institute Inc., Cary, NC, USA) was used for these analyses.

\section{Results}

Serum TSH concentrations throughout the study are shown in Fig. 1. At the time of diagnosis, TSH ranged from 5 to $>1000 \mathrm{U} / \mathrm{L}$ and in $64(42.9 \%)$ of them it was $<10 \mathrm{U} / \mathrm{L}$. At baseline before L-T4 discontinuation, TSH was $<5 \mathrm{U} / \mathrm{L}$ in all except 9 patients. Two months following discontinuation of treatment, TSH rose $>10 \mathrm{U} / \mathrm{L}$ in 37 patients $(25.3 \%, 5$ dropped out during follow-up). After 6 months, 13 more patients showed a TSH >10U/L 


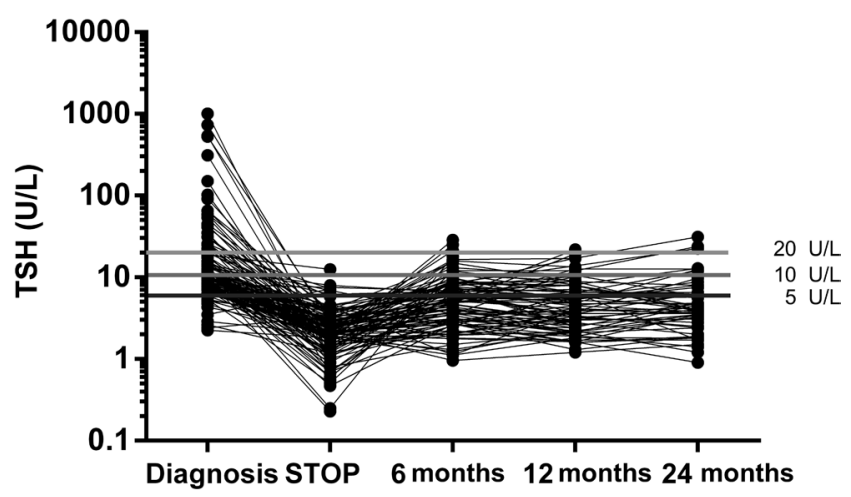

Figure 1

Serum TSH concentrations at diagnosis, at baseline and after discontinuation of L-thyroxine.

(9.1\% or 13/143). After 12 months, 12 more subjects (12/140, $8.6 \%, 3$ more lost) had a TSH >10U/L. After 24 months, 3 more subjects $(3 / 993.1 \%, 41$ lost) had a TSH $>10 \mathrm{U} / \mathrm{L}$.

At 12 months, a TSH between 5 and $10 \mathrm{U} / \mathrm{L}$ was observed in $25 / 140$ patients (17.9\%), while 53/140 patients (37.9\%) had a TSH $<5 \mathrm{U} / \mathrm{L}$.

At 24 months, 9/99 patients (9.1\%) had a TSH between 5 and $10 \mathrm{U} / \mathrm{L}$, and 25/99 (25.5\%) <5 U/L.

Altogether, 1 year after discontinuation of L-T4 78/140 (55.7\%, 8 patients were lost during follow-up) and after 2 years 34/99 (34.3\%, 49 patients lost during follow-up) still required no treatment.

The patients lost to follow-up were excluded from the statistical analysis. They were lost mainly because of poor compliance; none had biochemical and/or clinical evidence of hypothyroidism. We looked for possible differences between the patients who required resuming treatment (\#62) and those who did not (\#78), and the results are shown in Table 1 . Patients who restarted treatment were younger and showed significantly higher TSH and TGAb concentrations at the time of diagnosis, and higher concentrations of TPOAb and goiter at baseline. To verify whether a state of subclinical hypothyroidism might have exerted a negative influence during the first 12 months of the study, we evaluated the auxological parameters and the biochemical profile at baseline and after 12 months in 49 subjects who completed the study and for whom all data were available. No significant differences were found for the auxological parameters, lipid profile, glycemia, insulin serum concentrations and insulin sensitivity (QUICKI) (Table 2). Furthermore, no significant changes were found in goiter frequency $(39 \%$ vs $28 \%$; NS), TS $(2.52 \pm 1.23$ vs $2.36 \pm 1.12$; NS), TPOAb $(698 \pm 889$ vs $366 \pm 402 \mathrm{U} / \mathrm{mL} ; \mathrm{NS})$, and TGAb $(583 \pm 934$ vs $365 \pm 606 \mathrm{U} / \mathrm{mL}$; NS).

$$
\begin{aligned}
& \text { http://www.endocrineconnections.org } \\
& \text { DOI: 10.1530/EC-17-0023 }
\end{aligned}
$$

(C) 2017 The authors Published by Bioscientifica Ltd

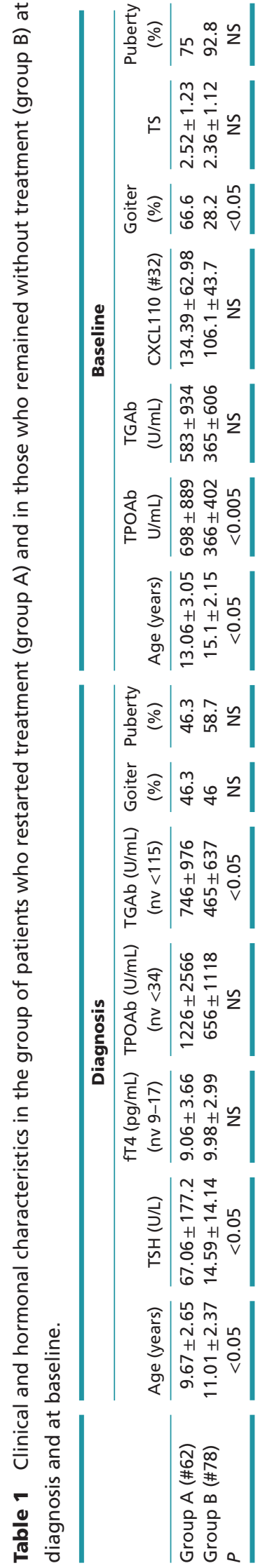
This work is licensed under a Creative Commons
Attribution-NonCommercial-NoDerivatives 4.0 International License. 
Table 2 Auxological and biochemical profile of the 78 patients who remained without treatment (group B) at baseline and after 12 months.

\begin{tabular}{|c|c|c|c|c|c|c|c|c|}
\hline & Height (SDS) & BMI (SDS) & Glucose (mg/dL) & Insulin (U/L) & QUICKI & Total-C (mg/dL) & HDL-C (mg/dL) & Triglycerides $(\mathrm{mg} / \mathrm{dL})$ \\
\hline Baseline & $-0.008 \pm 1.03$ & $-0.11 \pm 1.03$ & $79.6 \pm 6.6$ & $6.9 \pm 7.0$ & $0.4 \pm 0.0$ & $163.5 \pm 28.5$ & $59.9 \pm 13.7$ & $72.6 \pm 28.5$ \\
\hline 12 months & $0.004 \pm 0.91$ & $-0.09 \pm 0.99$ & $79.7 \pm 7.7$ & $7.0 \pm 4.2$ & $0.4 \pm 0.0$ & $163.1 \pm 25.0$ & $57.5 \pm 12.2$ & $71.2 \pm 21.8$ \\
\hline$P$ & NS & NS & NS & NS & NS & NS & NS & NS \\
\hline
\end{tabular}

HDL-C, high-density cholesterol; Total-C, total cholesterol.

TSH serum level at diagnosis was the only significant predictor of thyroid dysfunction after 2 months. We also found a significant correlation between TSH serum concentrations at diagnosis and those measured 2 months after stopping treatment $(P<0.01)$ (Fig. 2). ROC analysis showed that a patient with a TSH value at diagnosis $<10 \mathrm{U} / \mathrm{L}$ had $79 \%$ probability of not developing thyroid dysfunction after discontinuation of treatment.

\section{Discussion}

The aim of our study was to investigate whether children and adolescents with HT actually treated with L-thyroxine should be treated lifelong. We have previously shown that thyroid function can change over time, and that it improves or even normalizes in a significant number of patients $(6,7,8)$.

In the present study we have shown that two years after discontinuation of L-T4, 25.3\% of the patients had a normal thyroid function, while $9.1 \%$ showed mildly

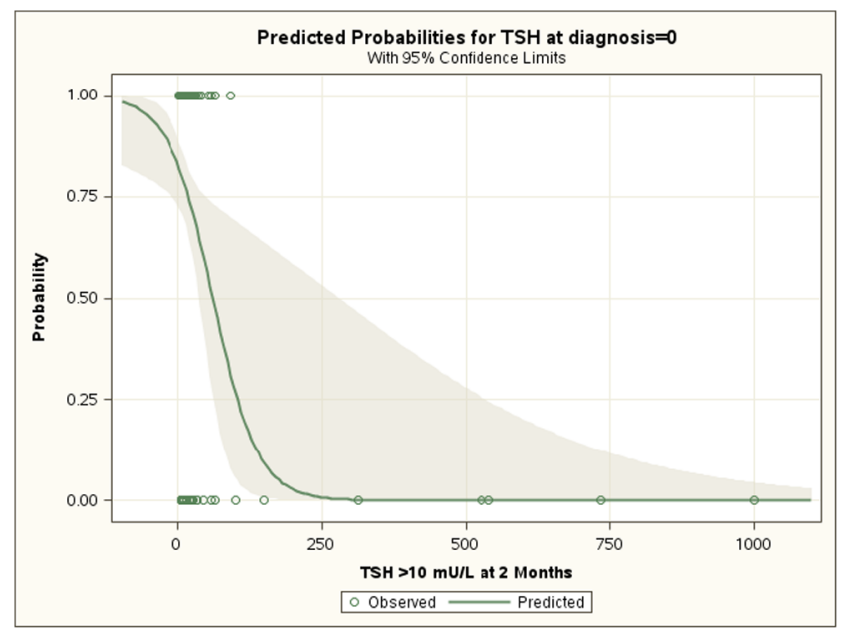

Figure 2

Effect plot obtained by logistic regression analysis showing the value (95\% confidence limits) of serum TSH concentrations at diagnosis in predicting the probability of not requiring re-institution of treatment 2 months after discontinuation of L-thyroxine. elevated TSH concentrations with normal fT4. At variance with adults, this condition of subclinical hypothyroidism or 'isolated hyperthyrotropinemia' does not cause any clinical consequence on growth $(6,7,8)$ and cognitive function (16) in children and adolescents. In this study, we confirm the relative safety of a mild TSH elevation, since we have not observed any adverse effect during the first 12 months of follow-up on growth, lipid profile, glucose homeostasis, and the development or worsening of goiter.

A recent study suggests that long-standing subclinical hypothyroidism may be associated with decreased concentrations of HDL cholesterol, but normal concentrations of triglycerides, total cholesterol and LDL cholesterol in children and adolescents (17). However, the patients of this study had an idiopathic form of hypothyroidism; therefore, differences in the cause of subclinical hypothyroidism, and in the duration of thyroid dysfunction, might all account for the discrepancies (18). On the other hand, the results of clinical trials with L-T4 have shown no beneficial effect on the lipid profile in patients with subclinical hypothyroidism. Increased insulin resistance has also been described in some studies $(19,20,21)$ but not in others $(22)$.

We believe that our preliminary findings are of clinical relevance in the management of children with HT. HT, however, is a chronic autoimmune disease and, as such, it may worsen with time and/or associate with other endocrine and non-endocrine disease. We previously showed that the presence of celiac disease, elevated TSH and TPOAb at diagnosis, and a progressive increase in TSH are predictive factors for thyroid failure in these patients (7). A continuous surveillance, not only of thyroid function, is thus mandatory. Thyroid ultrasound is particularly important, for the early detection of nodules, which seem to be more common than in the normal population (23), as well as for the assessment of thyroid volume. Furthermore, thyroid ultrasound may also reveal eventual modifications of thyroid volume in patients either on treatment or without treatment, also in euthyroid patients (24).

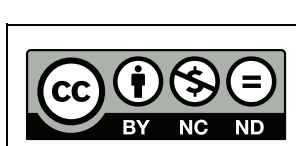
This work is licensed under a Creative Commons
Attribution-NonCommercial-NoDerivatives 4.0 International License. 
In order to identify the predictive factors which might aid in the decision of discontinuing treatment, we looked at parameters of disease activity such as antithyroid antibodies, the presence of goiter, the degree of hypoechogenity, and the concentrations of serum $\mathrm{TSH}$, and fT4. TSH serum concentrations at diagnosis $<10 \mathrm{U} / \mathrm{L}$ confers a $79 \%$ probability that re-institution of treatment will not be required. The high predictive value of TSH is further supported by the significant correlation between serum TSH at diagnosis and at 2 months after discontinuation of treatment. This suggests that there may be different degrees of severity of the disease and, although minor changes may be observed, patients tend to maintain the same degree of thyroid dysfunction. Our findings support this hypothesis, since the patients who restarted treatment showed a more severe form of HT at diagnosis as well as at baseline. In fact, in these patients the diagnosis was made at a younger age and their thyroid function was more severely affected, with higher concentrations of TPOAb and TGAb, and a more frequent presence of goiter. These findings are in agreement with those of Wasniewska and coworkers (25) who reported that L-T4 treatment does not influence the natural history of the disease. Reports in the adult population seem to support our findings of relative stability of subclinical hypothyroidism over time. Long-term follow-up studies show that although $5-8 \%$ per year of patients became frankly hypothyroid $(26,27,28,29,30), 6-35 \%$ per year show normalization of thyroid function.

We also measured chemokine CXCL10 as an index of autoimmune inflammation in a subset of patients. CXCL10 (a prototype Th1-oriented immunephenotype chemokine) plays a role in the initiation of HT and contributes to maintaining chronic autoimmune inflammation. It has been shown that CXCL10 is closely related to a more severe course of HT with development of hypothyroidism $(31,32,33)$. CXCL10 concentrations, however, were not different between groups.

Furthermore, regional differences in iodine concentration should not have influenced our results since a study reported no differences among the centers participating in the study (34).

Our results suggest that a substantial number of children with HT on treatment with L-T4 do not require lifelong treatment. Since TSH at diagnosis was a strong predictive factor of thyroid function, we suggest discontinuation of treatment in children with a TSH level at diagnosis $<10 \mathrm{U} / \mathrm{L}$. The absence of any clinical adverse effect after discontinuation of treatment supports this suggestion. Nonetheless, prolonged surveillance of thyroid function and morphology is required.

A weakness of our study is represented by the large number of patients lost to follow-up, mainly because of lack of compliance and not because symptomatic of hypothyroidism. However, their auxological characteristics and their thyroid function and morphology were similar to those who completed the study.

In conclusion, we have shown that LT4 treatment may be discontinued in some patients with HT. When and at which TSH serum level the treatment should be restarted remain a matter of debate, and require further studies.

\section{Declaration of interest}

The authors declare that there is no conflict of interest that could be perceived as prejudicing the impartiality of the research reported.

\section{Funding}

This research did not receive any specific grant from any funding agency in the public, commercial or not-for-profit sector.

\section{References}

1 Ozen S, Berk O, Simsek DG \& Darcan S. Clinical course of Hashimoto's thyroiditis and effects of levothyroxine therapy on the clinical course of the disease in children and adolescents. Journal of Clinical Research in Pediatric Endocrinology 20113 192-197. (doi:10.4274/jcrpe.425)

2 Lazarus J, Brown RS, Daumerie C, Hubalewska-Dydejczyk A, Negro R \& Vaidya B. 2014 European Thyroid Association Guidelines for the management of subclinical hypothyroidism in pregnancy and in children. European Thyroid Journal 20143 76-94. (doi:10.1159/000362597)

3 Padberg S, Heller K, Usadel KH \& Schumm-Draeger PM. One-year prophylactic treatment of euthyroid Hashimoto's thyroiditis patients with levothyroxine: is there a benefit? Thyroid 200111 249-255. (doi: 10.1089/105072501750159651)

4 Monzani A, Prodam F, Rapa A, Moia S, Agarla V, Bellone S \& Bona $\mathrm{G}$. Endocrine disorders in childhood and adolescence. Natural history of subclinical hypothyroidism in children and adolescents and potential effects of replacement therapy: a review. European Journal of Endocrinology 2013168 R1-R11. (doi:10.1530/ EJE-12-0656)

5 Rallison ML, Dobyns BM, Meikle AW, Bishop M, Lyon JL \& Stevens W. Natural history of thyroid abnormalities: prevalence, incidence, and regression of thyroid diseases in adolescents and young adults. American Journal of Medicine 199191 363-370. (doi:10.1016/00029343(91)90153-O)

6 Radetti G, Gottardi E, Bona G, Corrias A, Salardi S, Loche S \& Study Group for Thyroid Diseases of the Italian Society for Pediatric Endocrinology and Diabetes (SIEDP/ISPED). The natural history of euthyroid Hashimoto's thyroiditis in children. Journal of Pediatrics 2006149 827-832. (doi:10.1016/j.jpeds.2006.08.045)

7 Radetti G, Maselli M, Buzi F, Corrias A, Mussa A, Cambiaso P, Salerno M, Cappa M, Baiocchi M, Gastaldi R, et al. The natural history of the normal/mild elevated TSH serum levels in children and adolescents with Hashimoto's thyroiditis and isolated hyperthyrotropinaemia: http://www.endocrineconnections.org DOI: 10.1530/EC-17-0023
(๑) 2017 The authors Published by Bioscientifica Ltd
This work is licensed under a Creative Commons Attribution-NonCommercial-NoDerivatives 4.0 International License. 
a 3-year follow-up. Clinical Endocrinology 201276 394-398. (doi:10.1111/j.1365-2265.2011.04251.x)

8 Moore DC. Natural course of 'subclinical' hypothyroidism in childhood and adolescence. Archives of Pediatrics and Adolescent Medicine 1996150 293-297. (doi:10.1001/ archpedi.1996.02170280063012)

9 Wasniewska M, Aversa T, Salerno M, Corrias A, Messina MF, Mussa A, Capalbo D, De Luca F \& Valenzise M. Five-year prospective evaluation of thyroid function in girls with subclinical mild hypothyroidism of different etiology. European Journal of Endocrinology 2015173 801-808. (doi:10.1530/EJE-15-0484)

10 Aversa T, Valenzise M, Corrias A, Salerno M, De Luca F, Mussa A, Rezzuto M, Lombardo F \& Wasniewska M. Underlying Hashimoto's thyroiditis negatively affects the evolution of subclinical hypothyroidism in children irrespective of other concomitant risk factors. Thyroid 201525 183-187. (doi:10.1089/thy.2014.0235)

11 Battelino T, Krzisnik C, Gottschalk ME \& Zeller WP. Testing for thyroid function recovery in children and adolescents with Hashimoto thyroiditis. Annals of Clinical and Laboratory Science 199424 489-494.

12 Katz A, Nambi SS, Mather K, Baron AD, Follmann DA, Sullivan G \& Quon MJ. Quantitative insulin sensitivity check index: a simple, accurate method for assessing insulin sensitivity in humans. Journal of Clinical Endocrinology and Metabolism 200085 2402-2410. (doi:10.1210/jcem.85.7.6661)

13 Cacciari E, Milani S, Balsamo A, Spada E, Bona G, Cavallo L, Cerutti F, Gargantini L, Greggio N, Tonini G, et al. Italian cross-sectional growth charts for height, weight and BMI (2 to $20 \mathrm{yr}$ ). Journal of Endocrinological Investigation 200629 581-593. (doi:10.1007/BF03344156)

14 Tanner JM. Growth and Adolescence. Oxford, UK: Blackwell Scientific Publications, 1962

15 Rapa A, Monzani A, Moia S, Vivenza D, Bellone S, Petri A, Teofoli F, Cassio A, Cesaretti G, Corrias A, et al. Subclinical hypothyroidism in children and adolescents: a wide range of clinical, biochemical, and genetic factors involved. Journal of Clinical Endocrinology and Metabolism 200994 2414-2420. (doi:10.1210/jc.2009-0375)

16 Cerbone M, Bravaccio C, Capalbo D, Polizzi M, Wasniewska M, Cioffi D, Improda N, Valenzise M, Bruzzese D, De Luca F, et al. Linear growth and intellectual outcome in children with long-term idiopathic subclinical hypothyroidism. European Journal of Endocrinology 2011164 591-597. (doi:10.1530/EJE-10-0979)

17 Cerbone M, Capalbo D, Wasniewska M, Mattace Raso G, Alfano S, Meli R, De Luca F \& Salerno M. Cardiovascular risk factors in children with long-standing untreated idiopathic subclinical hypothyroidism. Journal of Clinical Endocrinology and Metabolism 201499 2697-2703. (doi:10.1210/jc.2014-1761)

18 Danese MD, Ladenson PW, Meinert CL \& Powe NR. Clinical review 115: effect of thyroxine therapy on serum lipoproteins in patients with mild thyroid failure: a quantitative review of the literature. Journal of Clinical Endocrinology and Metabolism 200085 2993-3001.

19 Toruner F, Altinova AE, Karakoc A, Yetkin I, Ayvaz G, Cakir N \& Arslan M. Risk factors for cardiovascular disease in patients with subclinical hypothyroidism. Advances in Therapy 200825 430-437. (doi:10.1007/ s12325-008-0053-7)

20 Baskin HJ, Cobin RH, Duick DS, Gharib H, Guttler RB, Kaplan MM, Segal RL \& American Association of Clinical Endocrinologists. American Association of Clinical Endocrinologists medical guidelines for clinical practice for the evaluation and treatment of hyperthyroidism and hypothyroidism. Endocrine Practice 20028 457-469. (doi:10.4158/1934-2403-8.6.457)

21 Maratou E, Hadjidakis DJ, Kollias A, Tsegka K, Peppa M, Alevizaki M, Mitrou P, Lambadiari V, Boutati E, Nikzas D, et al. Studies of insulin resistance in patients with clinical and subclinical hypothyroidism. European Journal of Endocrinology 2009160 785-790. (doi:10.1530/EJE08-0797)

22 Sridevi A, Vivekanand B, Giridhar G, Mythili A \& Subrahmanyan KA. Insulin resistance and lipid alterations in subclinical hypothyroidism. Indian Journal of Endocrinology and Metabolism 201216 (Supplement 2) S345-S346. (doi:10.4103/2230-8210.104085)

23 Corrias A, Cassio A, Weber G, Mussa A, Wasniewska M, Rapa A, Gastaldi R, Einaudi S, Baronio F, Vigone MC, et al. Thyroid nodules and cancer in children and adolescents affected by autoimmune thyroiditis. Archives of Pediatrics and Adolescent Medicine 2008162 526-531. (doi:10.1001/archpedi.162.6.526)

24 Dorr HG, Bettendorf M, Binder G, Karges B, Kneppo C, Schmidt H, Voss E, Wabitsch M \& Dötsch J. Levothyroxine treatment of euthyroid children with autoimmune hashimoto thyroiditis: results of a multicenter, randomized, controlled trial. Hormone Research in Paediatrics 201584 266-274. (doi:10.1159/000437140)

25 Wasniewska M, Corrias A, Aversa T, Valenzise M, Mussa A, De Martino L, Lombardo F, De Luca F \& Salerno M. Comparative evaluation of therapy with l-thyroxine versus no treatment in children with idiopathic and mild subclinical hypothyroidism. Hormone Research in Paediatrics 201277 376-381. (doi:10.1159/000339156)

26 Vanderpump MP, Tunbridge WM, French JM, Appleton D, Bates D, Clark F, Grimley Evans J, Hasan DM, Rodgers H, Tunbridge F, et al. The incidence of thyroid disorders in the community: a twenty-year follow-up of the Whickham Survey. Clinical Endocrinology 199543 55-68. (doi:10.1111/j.1365-2265.1995.tb01894.x)

27 Diez JJ \& Iglesias P. Spontaneous subclinical hypothyroidism in patients older than 55 years: an analysis of natural course and risk factors for the development of overt thyroid failure. Journal of Clinical Endocrinology and Metabolism 200489 4890-4897. (doi:10.1210/jc.2003-032061)

28 Kabadi UM. 'Subclinical hypothyroidism'. Natural course of the syndrome during a prolonged follow-up study. Archives of Internal Medicine 1993153 957-961. (doi:10.1001/archinte. 1993.00410080025004)

29 Parle JV, Franklyn JA, Cross KW, Jones SC \& Sheppard MC. Prevalence and follow-up of abnormal thyrotrophin (TSH) concentrations in the elderly in the United Kingdom. Clinical Endocrinology 199134 77-83. (doi:10.1111/j.1365-2265.1991.tb01739.x)

30 Huber G, Staub JJ, Meier C, Mitrache C, Guglielmetti M, Huber P \& Braverman LE. Prospective study of the spontaneous course of subclinical hypothyroidism: prognostic value of thyrotropin, thyroid reserve, and thyroid antibodies. Journal of Clinical Endocrinology and Metabolism 200287 3221-3226. (doi:10.1210/jcem.87.7.8678)

31 Antonelli A, Rotondi M, Fallahi P, Romagnani P, Ferrari SM, Buonamano A, Ferrannini E \& Serio M. High levels of circulating CXC chemokine ligand 10 are associated with chronic autoimmune thyroiditis and hypothyroidism. Journal of Clinical Endocrinology and Metabolism 200489 5496-5499. (doi:10.1210/jc.2004-0977)

32 Corona G, Biagini C, Rotondi M, Bonamano A, Cremonini N, Petrone L, Conforti B, Forti G \& Serio M. Correlation between, clinical, biochemical, color Doppler ultrasound thyroid parameters, and CXCL-10 in autoimmune thyroid diseases. Endocrine Journal $2008 \mathbf{5 5}$ 345-350. (doi:10.1507/endocrj.K07E-052)

33 Rotondi M, Chiovato L, Romagnani S, Serio M \& Romagnani P. Role of chemokines in endocrine autoimmune diseases. Endocrine Reviews 200728 492-520. (doi:10.1210/er.2006-0044)

34 Pastorelli AA, Stacchini P \& Olivieri A. Daily iodine intake and the impact of salt reduction on iodine prophylaxis in the Italian population. European Journal of Clinical Nutrition 201569 211-215. (doi:10.1038/ejcn.2014.206)

Received in final form 24 March 2017

Accepted 27 March 2017

Accepted Preprint published online 27 March 2017 